\title{
Synthesis of Silver Nanoparticles Using Buchu Plant Extracts and Their Analgesic Properties
}

Herbert Chiguvare ${ }^{1}$, Opeoluwa O. Oyedeji ${ }^{1, *}$, Reuben Matewu ${ }^{2}$, Olukayode Aremu ${ }^{3}$, Idris A. Oyemitan ${ }^{4}$, Adebola O. Oyedeji ${ }^{4}$, Benedicta N. Nkeh-Chungag ${ }^{5}$, Sandile P. Songca ${ }^{4}$, Sneha Mohan ${ }^{6}$ and Oluwatobi S. Oluwafemi ${ }^{6,7, *}$

1 Department of Chemistry, Faculty of Science and Agriculture, University of Fort Hare, Private Bag X1314, Alice 5700, South Africa; cherbert.jr@gmail.com

21124 Buchanan Street, Ginsburg, King William's Town 5601, Eastern Cape, South Africa; reubenmatewu@gmail.com

3 Department of Physiology, Faculty of Health Sciences, Walter Sisulu University, Nelson Mandela Drive Campus, Mthatha 5117, South Africa; snehakoottungal@yahoo.co.in

4 Department of Chemical and Physical Sciences, Faculty of Natural Sciences, Walter Sisulu University, Nelson Mandela Drive Campus, P. Bag X1, Mthatha 5117, South Africa; oyemix@yahoo.com (I.A.O.); aoyedeji@wsu.ac.za (A.O.O.); spsongca@wsu.ac.za (S.P.S.)

5 Department of Biological and Environmental Science Chemistry, Faculty of Natural Science, Walter Sisulu University, Nelson Mandela Drive Campus, P. BagX1, Mthatha 5117, South Africa; bnkehchungag@wsu.ac.za

6 Centre for Nanomaterials Science Research, University of Johannesburg, Johannesburg Doornfontein 2028, South Africa; snehamkoottungal@gmail.com

7 Department of Applied Chemistry, University of Johannesburg, Doornfontein Campus, P.O. Box 17011, Doornfontein 2028, Gauteng, South Africa

* Correspondence: OOyedeji@ufh.ac.za (O.O.O.); Oluwafemi.oluwatobi@gmail.com (O.S.O.); Tel.: +27-76-426-0280 (O.O.O.); +27-76-511-0322 (O.S.O.)

Academic Editors: Alexandru Mihai Grumezescu and Derek J. Mcphee Received: 20 March 2016; Accepted: 7 June 2016; Published: 14 June 2016

\begin{abstract}
We herein report for the first time the synthesis and analgesic properties of silver nanoparticles (Ag-NPs) using buchu plant extract. The as-synthesised Ag-NPs at different temperatures were characterised by UV-Vis spectroscopy, Fourier transform infra-red spectroscopy (FTIR) and transmission transform microscopy (TEM) to confirm the formation of silver nanoparticles. Phytochemical screening of the ethanolic extract revealed the presence of glycosides, proteins, tannins, alkaloids, flavonoids and saponins. The absorption spectra showed that the synthesis is temperature and time dependent. The TEM analysis showed that the as-synthesised Ag-NPs are polydispersed and spherical in shape with average particle diameter of $19.95 \pm 7.76 \mathrm{~nm}$ while the FTIR results confirmed the reduction and capping of the as-synthesised Ag-NPs by the phytochemicals present in the ethanolic extract. The analgesic study indicated that the combined effect of the plant extract and $\mathrm{Ag}-\mathrm{NPs}$ is more effective in pain management than both the aspirin drug and the extract alone.
\end{abstract}

Keywords: silver nanoparticles; analgesic activity; phytochemicals; buchu

\section{Introduction}

Synthesis of nanoparticles using plants extract has become one of the most common greener approaches since most plants are biocompatible and are safe to handle [1]. Plant mediated synthesis of silver nanoparticles makes use of the wide variability of functional groups available in the plant which can act as both reducing and capping agents [2,3]. Plant metabolites such as flavonoids and carbohydrate have been reported to act as electron shuttling agents for the reduction of silver ions to silver nanoparticles [3]. The electrostatic interactions and the hydrogen bond network between the 
silver nanoparticles and the phytochemicals provide stability to the nanoparticle system and control crystal growth [4].

Buchu plant belongs to the species betulina, genus Agathosma and the family Rutaceae [5]. It is native to South Africa and it is a plant well known for its production of essential oil [5]. The essential oil is used in the manufacture of flavourings and perfumes [6]. In traditional medical practice, buchu is most commonly taken orally in aqueous infusion extracts for external application as an antiseptic wash, cleansing of wounds and treating rheumatism [6]. It also has prominent uses as a remedy for indigestion, urinary tract infections and acute inflammation [7]. Thus, it is expected that the use of this plant in the synthesis of Ag-NPs will lead to a synergistic product with high medicinal value.

In view of the excellent properties of buchu plant, we herein report the synthesis of Ag-NPs using this plant and determine the analgesic property of the synergised product. As far as the authors know there are no reports on the synthesis of Ag-NPs using this plant and its analgesic properties. The synthesis was carried out at different temperatures and the as-synthesised Ag-NPs were characterised using UV-Vis spectroscopy, Fourier transform infra-red spectroscopy (FTIR) and transmission transform microscopy (TEM). The analgesic study shows that the combined effect of the plant extract and Ag-NPs is more effective in pain management than the both aspirin drug and the extract alone.

\section{Results and Discussion}

\subsection{Extraction and Phytochemical Screening}

The results from phytochemical screening of the ethanolic extract revealed the presence of glycosides, carbohydrates, flavonoids, alkaloids, steroids, terpenes, tannins, saponins and proteins as shown in Table 1.

Table 1. Phytochemical screening results.

\begin{tabular}{cc}
\hline Metabolite & Ethanolic Extract \\
\hline Glycosides & + \\
Flavonoids & + \\
Alkaloids & + \\
Terpenes & + \\
Steroids & + \\
Tannins & + \\
Saponins & + \\
Proteins & + \\
\hline &
\end{tabular}

\subsection{UV-Vis Analysis}

The absorption spectra for the as-synthesised Ag-NPs at different temperature is shown in Figure 1. The absorption spectra showed that the synthesis of silver nanoparticles mediated by buchu ethanolic extract is temperature and reaction time dependent. At $40{ }^{\circ} \mathrm{C}$, broad SPR peaks at $480 \mathrm{~nm}$ were observed indicating the presence of polydispersed nanoparticles. An increase in the temperature to $60{ }^{\circ} \mathrm{C}$ initially produced SPR peaks at $550 \mathrm{~nm}$. However, as the reaction time increased there was a blue shift in the SPR peak position to $430 \mathrm{~nm}$ indicating the formation of small particles. At $75^{\circ} \mathrm{C}$, the SPR peak become blues shifted at the beginning of the reaction indicating the formation of smaller particles compared to those synthesised at lower temperature. However, as the reaction time increased, the SPR peak position becomes red-shifted indicating increase in particle size. This observation is contrary to the result obtained at lower temperature in which the SPR peak position become blue-shifted as the reaction time increased. The formation of bigger particles at $75^{\circ} \mathrm{C}$ as the reaction time increased is attributed to aggregation due to the degradation of some thermo-labile phytochemicals that are 
present in the plant extract under high temperature as the reaction time increased. The degradation of these phytochemicals led to insufficient passivation of the Ag-NPs as the reaction continued and hence aggregation. Similar observation had been reported by Ahmad et al., for the biosynthesis of gold and silver NPs [8].
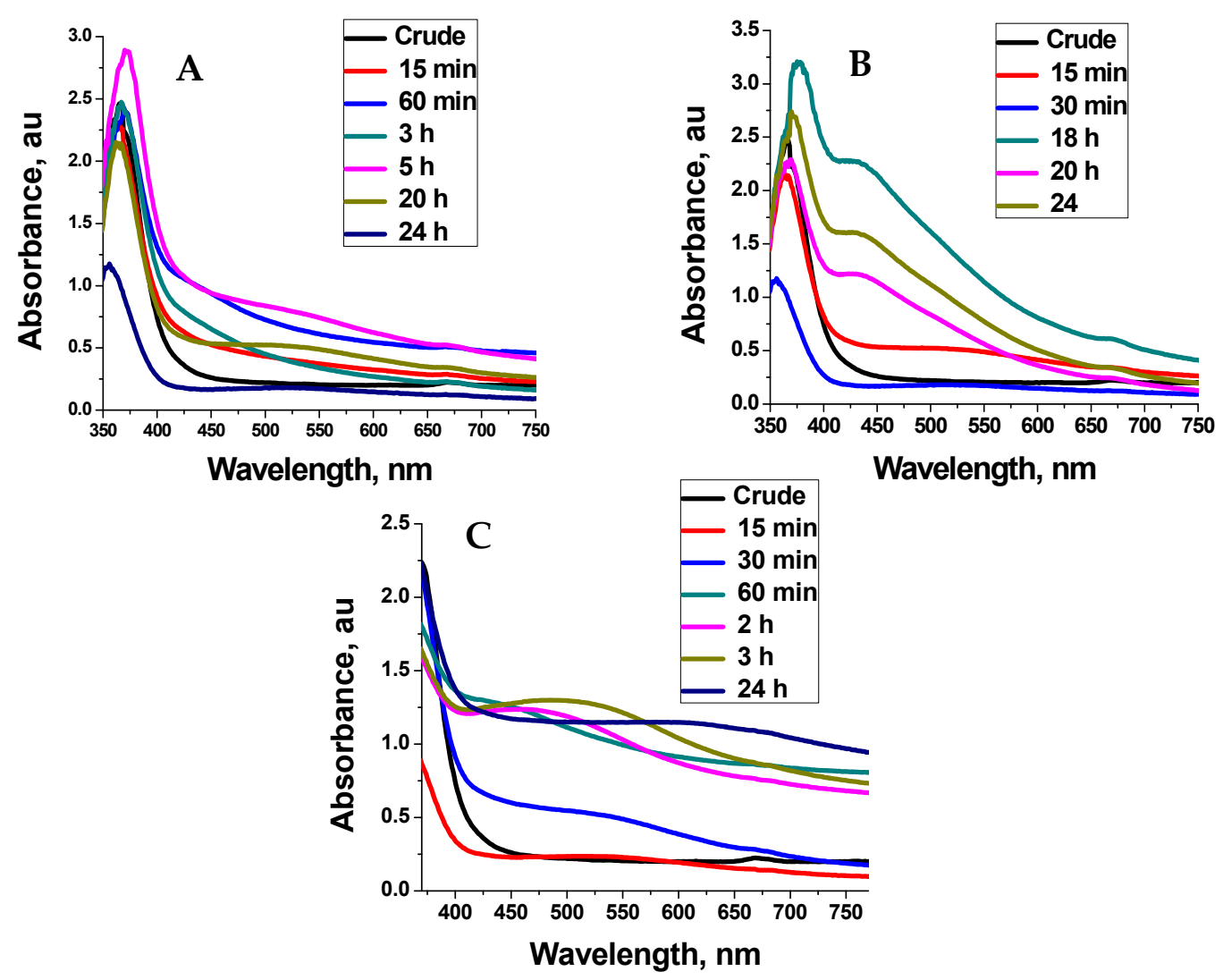

Figure 1. Absorption spectra for the Ag-nanoparticles synthesised at $40^{\circ} \mathrm{C}(\mathbf{A}) 60^{\circ} \mathrm{C}(\mathbf{B})$ and $75^{\circ} \mathrm{C}(\mathbf{C})$ at different reaction times.

\subsection{FTIR Analysis}

Figure 2 shows the FTIR spectra for the ethanolic extract and the as-synthesised Ag-NPs. The FTIR study of the extract and the Ag-NPs showed absorption bands corresponding to functional groups found in secondary metabolites. This indicated that secondary metabolites are involved in the synthesis of Ag-NPs. The prominent peaks in the extract were 3400, 2900 and $1100 \mathrm{~cm}^{-1}$. The prominent peaks in the silver nanoparticles were 396, 460, 2900 and $3400 \mathrm{~cm}^{-1}$. The broad peak in the crude at $3400 \mathrm{~cm}^{-1}$ is typical of a hydroxyl group from carbohydrates and amides. The peak at $2900 \mathrm{~cm}^{-1}$ indicates the presence of alkyl groups while $1100 \mathrm{~cm}^{-1}$ signifies the presence of C-O functional groups $[9,10]$. Phytochemical screening of the crude confirmed the presence of proteins, carbohydrates and flavonoids. Alcohols have been reported to facilitate the reduction of silver ions to silver nanoparticles while they are oxidised to carbonyl compounds [10]. Flavonoids are capable of releasing free reactive hydrogen during their keto-enol tautomeric transformations which can also facilitate the reduction of silver ions to silver nanoparticles [11]. Further analysis of the Ag-NPs spectra revealed that the first two bands at $396 \mathrm{~cm}^{-1}$ and $460 \mathrm{~cm}^{-1}$ originate from Ag-NPs ligand stretching vibrations that appear due to interaction of bio-molecules with the nanoparticle [12]. The absorption band at $3400 \mathrm{~cm}^{-1}$ indicates the presence of $\mathrm{NH}$ groups or $\mathrm{OH}$ bonded to a carbohydrate. This shows that the $\mathrm{NH}$ and $\mathrm{OH}$ groups among a host of other functional groups could be broadly responsible for the reduction of ionic silver to zero valent silver nanoparticles [11]. The peak at $2900 \mathrm{~cm}^{-1}$ is attributed to the alkane stretching band. The decrease in intensity between the extract and the nanoparticles 
indicates a realignment of $\mathrm{C}-\mathrm{H}$ bonds of the organic compounds in the crude during the nanoparticle synthesis [9]. The peaks observed from FTIR analysis confirm the reduction and capping of the as-synthesised Ag-NPs by the phytochemicals present in the ethanolic extract.

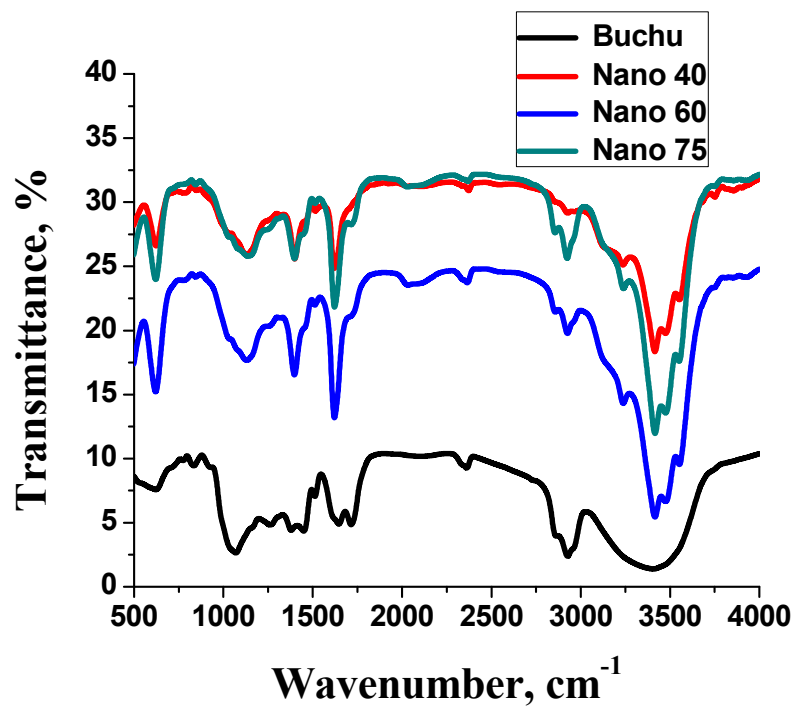

Figure 2. Fourier transform infra-red spectroscopy (FTIR) spectra of buchu ethanolic extract and as-synthesised silver nanoparticles (Ag-NPs) at different temperatures.

\subsection{TEM Analysis}

Figure 3 shows the representative TEM image and size distribution of buchu ethanolic extracts synthesised Ag-NPs at $60{ }^{\circ} \mathrm{C}$. The micrograph (Figure 3A) shows a mixture of small and bigger particles that are spherical and oblong in shapes. The size distribution curve (Figure 3B) shows that the particles are in the range 5-60 $\mathrm{nm}$ with average particle diameter of $19.95 \pm 7.76 \mathrm{~nm}$.
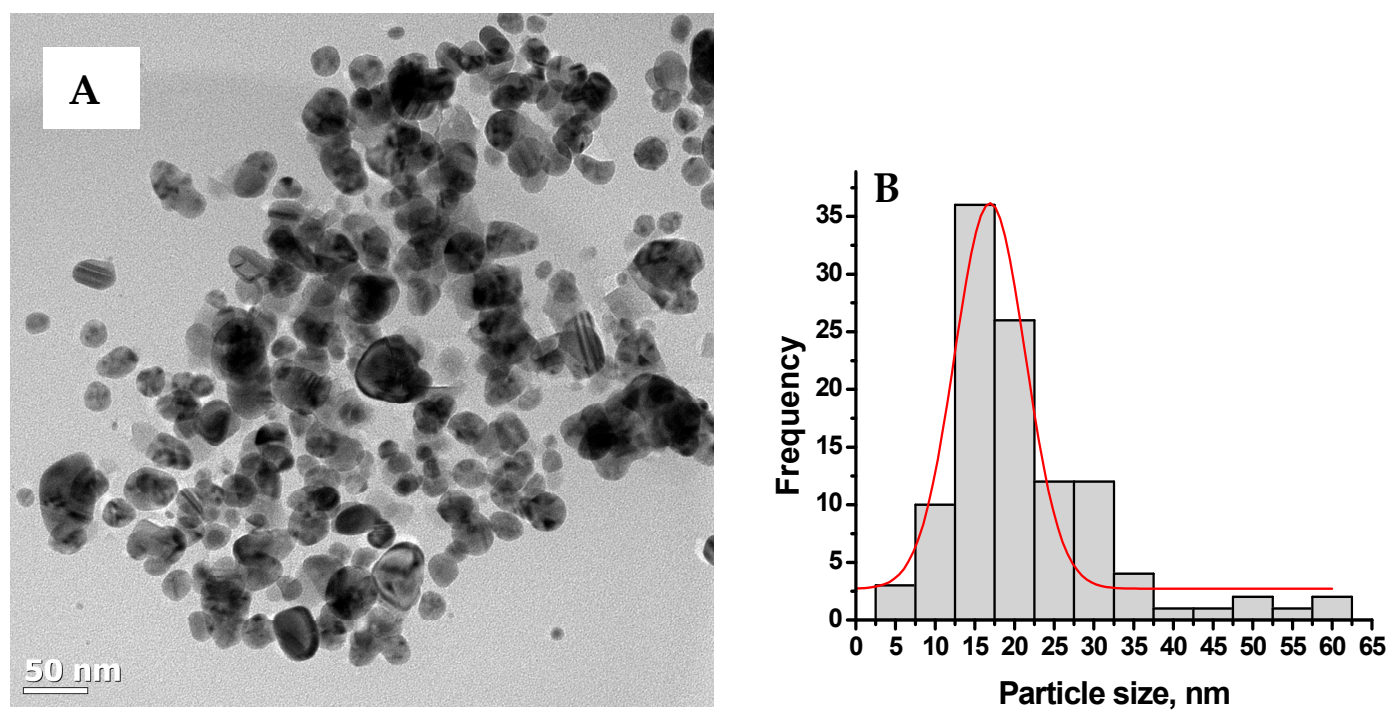

Figure 3. Typical transmission transform microscopy (TEM) images of Ag-NPs synthesised at $60{ }^{\circ} \mathrm{C}$ (A) and their size distribution (B).

\subsection{Analgesic Activity}

The results obtained from analgesic activity test show that all the as-synthesised Ag-NPs significantly reduced the number of paw licks at a dosage of $200 \mathrm{mg} / \mathrm{kg}$. The inhibition values 
for all the as-synthesised Ag-NPs are between 73\% and 98\% $(p<0.05)$ for the neurogenic phase and between $55 \%-80 \%$ for the anti-inflammatory phase. The inhibition values for buchu crude are $55 \%$ and $45 \%$ for the neurogenic and the anti-inflammatory phase respectively. The inhibition values for the positive control (Aspirin) are $84 \%$ and $81 \%$ for the neurogenic and the anti-inflammatory phase respectively $(p<0.05)$. The Ag-NPs significantly reduced the number of paw licks, indicating that the as-synthesised Ag-NPs have the ability to inhibit the action of pain mediators (Figure 4).

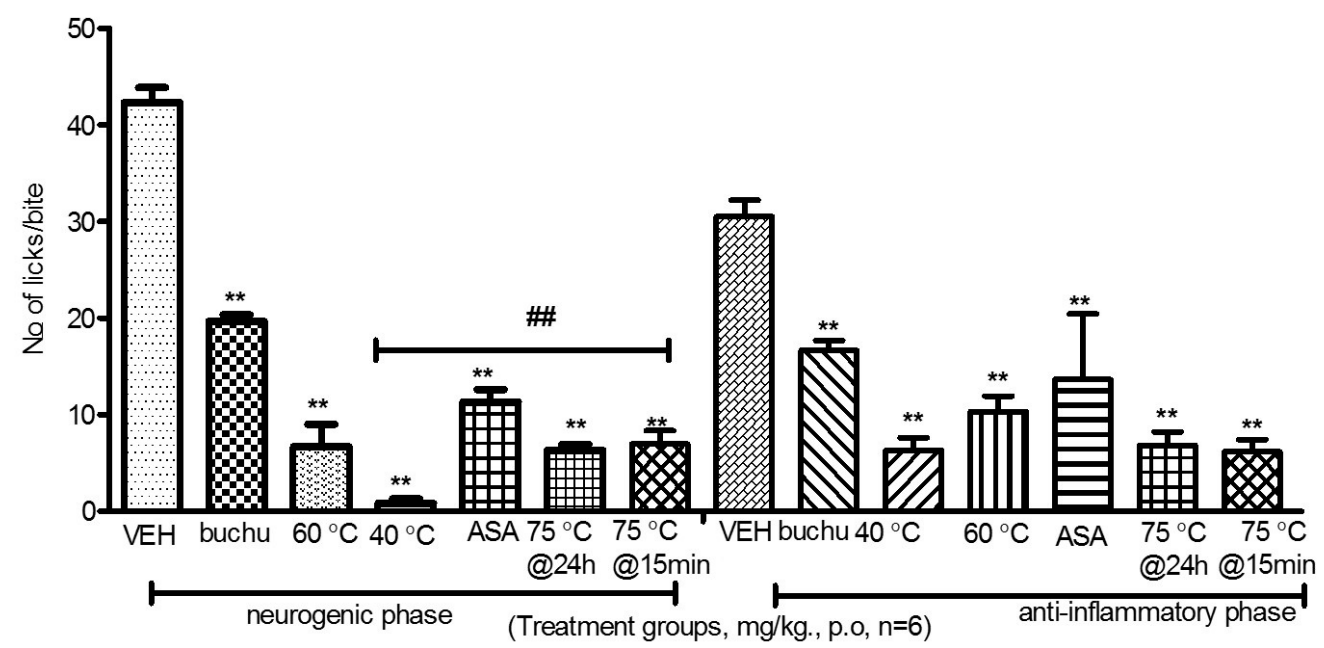

Figure 4. Effect of nanoparticles on paw licking in mice. ${ }^{* *} p<0.01$ statistically lower than the vehicle. \#\# $p<0.01$ statistically lower compared to buchu crude extract. VEH is the vehicle; ASA is Aspirin drug; $40{ }^{\circ} \mathrm{C}, 60^{\circ} \mathrm{C}$ and $75^{\circ} \mathrm{C}$ are the nanoparticles synthesized at $40{ }^{\circ} \mathrm{C}, 60^{\circ} \mathrm{C}$ and $75^{\circ} \mathrm{C} ; 75^{\circ} \mathrm{C} @ 15 \mathrm{~min}$ are nanoparticles synthesized at $75{ }^{\circ} \mathrm{C}$ harvested after $15 \mathrm{~min} ; 75^{\circ} \mathrm{C} @ 24 \mathrm{~h}$ are nanoparticles synthesized at $75^{\circ} \mathrm{C}$ harvested after $24 \mathrm{~h}$.

Analysis of variance between the experimental groups showed that the inhibition values of the nanoparticles were significantly higher than those administered with buchu ethanolic extract alone and aspirin. This has been attributed to the synergistic effect between the plant secondary metabolites and Ag-NPs. Furthermore, the Ag-NPs significantly inhibited the effect of inflammation mediators such as prostaglandins and its derivatives that cause pain and inflammation more than both aspirin and the ethanolic extract [13]. The nanoparticles produced at $75^{\circ} \mathrm{C}$ at $15 \mathrm{~min}$ reaction time had the smallest inhibition values for both the neurogenic and anti-inflammatory phase among the as-synthesised Ag-NPs. This has been attributed to the low activity of the plant extract at the beginning of the reaction. These results show that the combined effects of the plant extract and Ag-NPs are more effective than buchu extracts in the management of pain.

\section{Materials and Methods}

\subsection{Plant Material and Preparation of Extract}

Buchu plant material was obtained from King William's Town in the Eastern Cape Province of South Africa and authenticated at Botany Department, Walter Sisulu University. The plant material (leaves) was cleaned, air dried at $20^{\circ} \mathrm{C}-25^{\circ} \mathrm{C}$ and prepared for solvent extraction using ethanol $(95 \% v / v)$. The extract obtained was filtered and concentrated using a vacuum evaporator at $30{ }^{\circ} \mathrm{C}$. The ethanolic extract was screened for secondary metabolites (tannins, flavonoids, saponins, steroids, terpenes, glycosides, proteins and alkaloids) using phytochemical screening methods as described by Harbone and Sofowora [14,15]. 


\subsection{Synthesis of Silver Nanoparticles}

Thirty grams of buchu ethanolic extract were dissolved in $100 \mathrm{~mL}$ of water and filtered to create a stock solution. From this stock solution $10 \mathrm{~mL}$ was taken and mixed with $10 \mathrm{~mL}$ of $0.1 \mathrm{M} \mathrm{AgNO}_{3}$. This mixture was diluted to $50 \mathrm{~mL}$ with distilled water and heated to $40{ }^{\circ} \mathrm{C}$ under continuous stirring. Aliquots were taken at different reaction time to monitor the growth of Ag-NPs. The experiment was repeated at different temperatures of $60^{\circ} \mathrm{C}$ and $75^{\circ} \mathrm{C}$.

\subsection{Characterisation}

The reduction of Ag-NPs was monitored using UV 1650 PC-Shimadzu B UV-visible spectrophotometer (Shimadzu, Osaka, Japan). TEM analysis was carried out using a JEOL JEM 2100 (TEM) operated at $200 \mathrm{KV}$. Samples were mounted on a carbon coated grid. FTIR analysis was done by using a Perkin Elmer Spectrophotometer (Los Angeles, CA, USA).

\subsection{Analgesic Activity}

Forty two Swiss albino mice weighing 20-32 g of both sexes were obtained from the animal room at Walter Sisulu University. Room temperature was maintained at $24^{\circ} \mathrm{C}$ while lighting was provided exclusively by daylight. All the animals were used according to the Walter Sisulu Ethical Clearance Committee (No. 0009/07) ethics. The formalin test was carried out to test for analgesic activity as described by Prabhu et al. with some modifications [16]. The mice were divided into seven groups as follows:

- Control group $-0.9 \% w / v$ (normal saline)

- Standard group-100 $\mathrm{mg} / \mathrm{kg}$ aspirin

- Group III-200 mg/kg ethanolic extract

- Group IV-200 mg/ $\mathrm{kg}$ of nano particles produced at $40^{\circ} \mathrm{C}$

- Group V-200 mg/kg of nano particles produced at $60^{\circ} \mathrm{C}$

- Group VI-200 $\mathrm{mg} / \mathrm{kg}$ of nano-particles at $75^{\circ} \mathrm{C}$ (15 min reaction time)

- Group VII-200 $\mathrm{mg} / \mathrm{kg}$ nanoparticles produced at $75^{\circ} \mathrm{C}$ ( $24 \mathrm{~h}$ reaction time)

The control group received $0.9 \% \mathrm{NaCl}(10 \mathrm{~mL} / \mathrm{kg})$, the standard group received aspirin, group III received buchu extract, and groups IV-VII received the nanoparticles. One hour $(1 \mathrm{~h})$ after treatment with the various drugs, animals were injected sub-plantarly with a $100 \mu \mathrm{L}$ of $2.5 \%$ formalin solution (diluted in saline). Animals responded to formalin injection by licking the injured paw. The number of times the mice licked the paw was recorded during the first 5 min (neurogenic phase) and then 20 to $30 \mathrm{~min}$ (inflammatory phase) after formalin injection. \% inhibition $=(1-(\mathrm{T} / \mathrm{C})) \times 100$. $\mathrm{T}$ is the number of times treated mice licked the injured paw and $\mathrm{C}$ is the number of times control mice licked the treated paw.

\section{Conclusions}

Green synthesis of silver nanoparticles and its analgesic activities using buchu ethanolic extract is reported for the first time. The Ag-NPs showed significant inhibition of pain as compared to aspirin a standard analgesic drug at a dosage of $200 \mathrm{mg} / \mathrm{kg}$. The high inhibition values obtained in the analgesic test for the as-synthesised Ag-NPs compared to the extract is attributed to the synergistic effect between the plant secondary metabolites and Ag-NPs. These analyses show that as-synthesised Ag-NPs can be used in the management of pain.

Acknowledgments: This work was supported by Walter Sisulu University Mthatha, Govan Mbeki Research and Development centre, University of Fort Hare Alice and the National Research Foundation (NRF-IKS).

Author Contributions: Herbert Chiguvare and Opeoluwa O. Oyedeji performed the experiment, Rueben Matewu supplied the plant with information on its local usage in the community, Idris A. Oyemitan and Adebola O. Oyedeji, did the extraction and the phytochemical screening, Olukayode Aremu and Benedicta N. Nkeh-Chungag carried 
out the analgesic test and discussed the result. Sandile P. Songca, did the nano-characterizations and contributed to the manuscript write up, Sneha Mohan and Oluwatobi S. Oluwafemi conceptualized and designed the experiment, wrote part of manuscript and did all the editorial work.

Conflicts of Interest: The authors declare no conflict of interest. The founding sponsors had no role in the design of the study; in the collection, analyses, or interpretation of data; in the writing of the manuscript, and in the decision to publish the results.

\section{References}

1. Coetzee, C.; Jesthas, J.; Rintein, E. Indigenous Plant Genetic Resources of South Africa. Perspectives on New Crops and New Uses; ASHS Press: Alexandria, VA, USA, 1999; pp. 160-163.

2. Viljoen, A.M.; Moola, A.; van Vuuren, S.F.; Van Zyl, R.I.; Baser, K.H.C. The biological activity and essential oil composition of 17 Agathosma (Rutaceae) species. J. Essent. Oil Res. 2006, 18, 2-16.

3. Posthumous, M.A.; Van Beek, T.A.; Collins, N.F.; Graven, E.F. Chemical composition of the essential oil of Agathosma betulina, A. crenulata and an A. betulina $\times$ crenulata hybrid (Buchu). J. Essent. Oil Res. 1996, 8, 223-228. [CrossRef]

4. Firdhouse, J.M.; Lalitha, P.; Sripathi, K.S. Novel Synthesis of nanoparticles using leaf ethanol extract of Pisonia grandis. Pharm. Chem. 2012, 4, 2320-2326.

5. Sharma, V.K.; Yngard, R.A.; Lin, Y. Silver nanoparticles: Green synthesis and their antimicrobial activities. Adv. ColloidInterface Sci. 2009, 145, 83-96. [CrossRef] [PubMed]

6. El-Sheikh, M.A.; El-Rafie, S.M.; Abdel-Halim, E.S.; El-Rafie, M.H. Green Synthesis of Hydroxyethyl Cellulose-Stabilized Silver Nanoparticles. Polym. J. 2013, 2013, 1-11. [CrossRef]

7. Harborne, A.J. Phytochemical Methods: A Guide to Modern Techniques of Plant Analysis; Chapman and Hall Ltd.: London, UK, 1973.

8. Arunachalam, K.D.; Annamalai, S.K.; Hari, S. One step green synthesis of leaf extract-mediated biocompatible silver and gold nanoparticles from Memecylon umbellatum. Int. J. Nanomed. 2013, 8, 1307-1315. [CrossRef] [PubMed]

9. Thilagam, M.; Tamiselvi, A.; Chandrasekeran, B.; Rose, C. Photosynthesis of silver nanoparticles using medicinal and dye yielding plant of Bixa orellana L. leaf extract. JPSI 2013, 2, 9-13.

10. Ghosh, S.; Patil, S.; Ahire, M.; Kitture, R.; Kale, S. Synthesis of silver nanoparticles using Dioscora bulbifera tuber extract and evaluation of its synergistic potential in combination with antimicrobial agents. Int. J. Nanomed. 2012, 7, 483-496.

11. Jancy, M.E.; Inbathamizh, L. Green Synthesis and Characterization of Nano Silver Using Leaf Extract of Morinda pubescens. Asian J. Pharm. Clin. Res. 2012, 5, 1-5.

12. Harriot, M.; Marion, E.; Martha, A.; Welford, S.; William, A. Inflammation induced by histamine, serotonin, bradykinin, and compound 48/480 in the rat. Antagonists and mechanisms of action. J. Pharmacol. Exp. Ther. 2004, 19, 300-302.

13. Morteau, O. Prostaglandins and Inflammation: The cyclooxygenase controversy. Arch. Immunol. Ther. Exp. (Warsz) 2000, 48, 473-480. [PubMed]

14. Sofowora, A. Screening plants for bioactive agents. In Medicinal Plants and Traditional Medicinal in Africa, 2nd ed.; Spectrum books Ltd.: Ibadan, Nigeria, 1993.

15. Prabhu, V.V.; Nalini, G.; Chidambaranathan, N.; Kisan, N.S. Evaluation of Anti-inflammation and analgesic activity of Tridax procumbens Linn against formalin, acetic acid and CFA induced pain models. Int. J. Pharm. Pharm. Sci. 2011, 3, 126-130.

16. Ahmad, T.; Wani, I.A.; Manzoor, N.; Ahmed, J.; Asiri, A.M. Biosynthesis, structural characterization and antimicrobial activity of gold and silver nanoparticles. Colloids Surf. B 2013, 107, 227-234. [CrossRef] [PubMed]

Sample Availability: Samples of the compounds are available from the authors.

(C) 2016 by the authors; licensee MDPI, Basel, Switzerland. This article is an open access article distributed under the terms and conditions of the Creative Commons Attribution (CC-BY) license (http:/ / creativecommons.org/licenses/by/4.0/). 